\title{
Assessment of the Interaction of Aggregatin Protein with Amyloid-Beta (A $\beta)$ at the Molecular Level via In Silico Analysis
}

\author{
Nail Besli ${ }^{1}$ and Guven Yenmis ${ }^{2, *}$ \\ ${ }^{1}$ Department of Medical Biology, Faculty of Medicine, University of Health Sciences, Istanbul, Turkey \\ ${ }^{2}$ Department of Medical Biology, Faculty of Medicine, Biruni University, Istanbul, Turkey \\ *Corresponding author: E-mail: gyenmis@biruni.edu.tr; guvenyenmis@yahoo.com
}

Received: 06-08-2020

\begin{abstract}
Alzheimer's disease is a major neurodegenerative illness whose prevalence is increasing worldwide but the molecular mechanism remains unclear. There is some scientific evidence that the molecular complexity of Alzheimer's pathophysiology is associated with the formation of extracellular amyloid-beta plaques in the brain. A novel cross- phenotype association analysis of imaging genetics reported a brain atrophy susceptibility gene, namely FAM222A and the protein Aggregatin encoded by FAM222A interacts with amyloid-beta (A $\beta$ )-peptide (1-42) through its $\mathrm{N}$-terminal A $\beta$ binding domain and facilitates $A \beta$ aggregation. The function of Aggregatin protein is unknown, and its three-dimensional structure has not been analyzed experimentally yet. Our goal was to investigate the interaction of Aggregatin with $A \beta$ in detail by in silico analysis, including the 3D structure prediction analysis of Aggregatin protein by homology modeling. Our analysis verified the interaction of the $\mathrm{C}$-terminal domain of model protein with the $\mathrm{N}$-terminal domain of $\mathrm{A} \beta$. This is the first attempt to demonstrate the interaction of Aggregatin with the $A \beta$. These results confirmed in vitro and in vivo study reports claiming FAM222A helping to ease the aggregating of the $\mathrm{A} \beta$-peptide.
\end{abstract}

Keywords: Alzheimer's disease; amyloid-Beta; aggregatin; protein-peptide docking; protein structure prediction

\section{Introduction}

Alzheimer's disease (AD) is observed as a widespread and incurable ailment worldwide because of the elevated average human lifespan in recent years. Although the risk factors described as an increased lifetime and aging; the classic Mendelian inheritance with autosomal dominant pattern and multi-factorial features have also suggested as possible risk factors. The elevation of $\mathrm{AD}$ patient number in the population has become a social and an economic problem as an $\mathrm{AD}$ patient becomes dependent on another person. ${ }^{1,2}$ The global number of $\mathrm{AD}$ patients who have dementia was estimated to be 43.8 million worldwide ${ }^{3}$ and over 5 million in the USA. Through the middle of the century, this number may dramatically increase in the USA to 13.8 million people with Alzheimer's dementia. ${ }^{4}$

The neuropathology indicator of $\mathrm{AD}$, which in turn leads to dementia, is the presence of neurofibrillary tangles inside the cell, and the formation of amyloid-beta $(A \beta)$ peptides out of the cell, resulting in cerebral atrophy. ${ }^{5}$ One of these main pathologic characteristics of $A D, A \beta$ aggre- gation results from the presence of oligomeric $A \beta$ due to the processing of proteolytic lysis of the amyloid precursor protein (APP) in an inaccurate form and finally aggregation in $\mathrm{A} \beta$ fibrils and plaques as an intracellular lesion. ${ }^{6}$ It is unclear what the exact function of APP is, however, its role in cell growth and biological activities including signal transduction and neuronal development has been shown in several studies. ${ }^{7}$

Understanding the crucial patterns of the origin of the $A \beta$ pathology is based on figuring out the mechanisms that show how the monomers that build up the $A \beta$ aggregates are formed and how oligomeric clusters form the lesions. Many erroneous peptides formed by proteolytic processing of APP might be the major basis on the neuronal dysfunction in $\mathrm{AD}$. These peptides are mostly being encountered in the hippocampus region in the brain. ${ }^{8}$ The cleavage of APP may be processed in two alternative pathways, non-amyloidogenic and amyloidogenic, respectively. In the non-amyloidogenic proteolytic pathway, for example, APP is normally processed through a-secretase and $\lambda$-secretase, producing soluble peptides, while it forms 
indissoluble fragments as amyloid-beta peptides that aggregate in the amyloidogenic process. ${ }^{69}$ Further investigations are required to clarify the mechanisms associated with $\mathrm{AD}$ in the case of aggregation of these peptides after proteolytic processing.

The amino acid(aa) sequence of $A \beta 42$ from amyloid plaques was initially uncovered in the 1980s for the first time. ${ }^{10} \mathrm{~A} \beta$ is commonly thought to be intrinsically unstructured and therefore cannot be crystallized by standard techniques. Hence, various studies were deduced on the structure optimization that can preserve $A \beta$ peptides. The $3 \mathrm{D}$ structure of various $A \beta$ peptides was identified by the experimental tools including nuclear magnetic resonance (NMR, PDB: 1AMC, 1AMB, 1BA4, 1IYT, 1QWP, 1Z0Q) and X-ray crystallography (PDB: 2Y29, 4M1C, 4MVI, $4 \mathrm{MVK}, 4 \mathrm{MVL}$ ). Not interestingly, most of the information about the structure of $A \beta$ was gained from NMR and molecular dynamics. ${ }^{9}$ Attained models of $A \beta$ peptide structure (1-28) by NMR represented a conversion-folding of $\alpha$-helix into the $\beta$-sheet structure- taking place during the early stages of amyloid deposition in the AD. ${ }^{10} \mathrm{~A} \beta$ peptide (1-28) is the main part of the amyloid plaques in $\mathrm{AD}$ and histidine-13 and lysine- 16 of its chains are on the same face of the helix. Also, $A \beta(1-40)$ peptide in the physiological condition is present in an $\alpha$-helical structure whilst amyloid fibrils by these proteins shaped $\beta$-sheet structures. This structural modulation from $\alpha$-helix to $\beta$-sheet is considered as the critical step in the formation of aggregation. ${ }^{9}$

Most of the studies carried out in vivo and in vitro so far have been focused on elucidating their molecular complexity concerning the accumulation of amyloid-beta and the hyperphosphorylated microtubule protein tau in the pathology of Alzheimer. In a very recent study, Yan and et al. have reported that a brain atrophy susceptibility geneFAM222A (Family 222 member A) agglomerates in amyloid deposits, interacting by amyloid- $\beta(A \beta)$ via its $N$-terminal $A \beta$ binding domain. The expression of the protein synthesized termed as Aggregatin was typically detected in the brain and spinal cord of the central nervous system (CNS) using a specific antibody in vitro. The length of Aggregatin is 452 aa long and its function is still uncertain. In this survey, they showed how FAM222A accumulation interacts physically with amyloid- $\beta$ via its $\mathrm{N}$-terminal $\mathrm{A} \beta$ binding domain. This is one of the most critical studies performed on a patient with $\mathrm{AD}$ and in an $\mathrm{AD}$ mouse model that shed a light on the pathophysiology of AD. ${ }^{5}$

In the current study, we aimed to predict the three-dimensional structure of Aggregatin using various approaches considering the findings that show the interaction of the molecules of interest. The molecular docking was also performed based on the inspiration of this founding. We used homology modeling to obtain model proteins and then performed a protein-peptide docking study with several approaches. The prediction of protein structure by homology modeling has been performed broadly for folding proteins whereas it is limited in misfolded pro- tein and aggregate applications. As summarized in Figure 1 , we used all authenticated/trusted bioinformatics tools to predict the three-dimensional structure of Aggregatin protein. To increase the accuracy and docking performance of the model protein, we subjected the model proteins from each bioinformatics server to two different tools for the structural-quality analysis and preferred the higher quality one. Besides, we monitored the domain analysis on the primer structure of Aggregatin and predicted which part of its amino acids related to the localization in the plasma membrane. On the other hand, we investigated functionally similar genes with the FAM222A gene.

More mechanistic studies are necessary to get sufficient information about the 3D structure and the characterization of the FAM222A gene product association with Alzheimer's pathology. Considering the critical roles of Aggregatin, it is fundamental to pinpoint its physicochemical characteristics at the atomic structure level. Our computational approach based results will broaden the horizon of our knowledge on the pathogenesis of $\mathrm{AD}$ and support to clarify a candidate protein to play a possible critical role in amyloidosis.

\section{Materials and Methods}

\section{1. Prediction of the 3D Structure of Aggregatin by Homology Modeling}

All the work-flow was summarized in Fig.1. The protein sequence encoded by Human FAM222A (Reference Sequence: NP_116218.2) and FAM222B (Family 222 member B) (UniProtKB/Swiss-Prot: Q8WU58.1) from NCBI in FASTA format were fetched from NCBI in FASTA format, PSIPRED ${ }^{11}$ was used to predict the secondary structure of the Aggregatin. The amino acid sequence was subjected to I-TASSER ${ }^{12}$, PHYRE ${ }^{2}{ }^{13}$, Robetta ${ }^{14,15}$ common tools for based-homology modeling to have a tertiary structure of Aggregatin as a model,. The Qualitative Model Energy Analysis (QMEANDisCo) ${ }^{16}$ and ProSAweb ${ }^{17}$ tools were used for the quality control of model proteins.

\section{2. Sequence Analysis}

PSI-BLAST (Position-Specific Iterated BLAST) ${ }^{18}$ was performed for pairwise. All general and scoring parameters including MATRIX: BLOSUM62 and the threshold value (0.005) were left as the default settings. The primary structure of the sequence was predicted using DomPred ${ }^{19}$ (Protein Domain Prediction) and the outputs were interpreted in Jalview 2.11.0. ${ }^{20}$

\section{3. Visualization of Molecular Docking}

The primary structure of Aggregatin was visualized using Jalview 2.11 and the $\mathrm{PyMOL}^{21}$ software was used to 


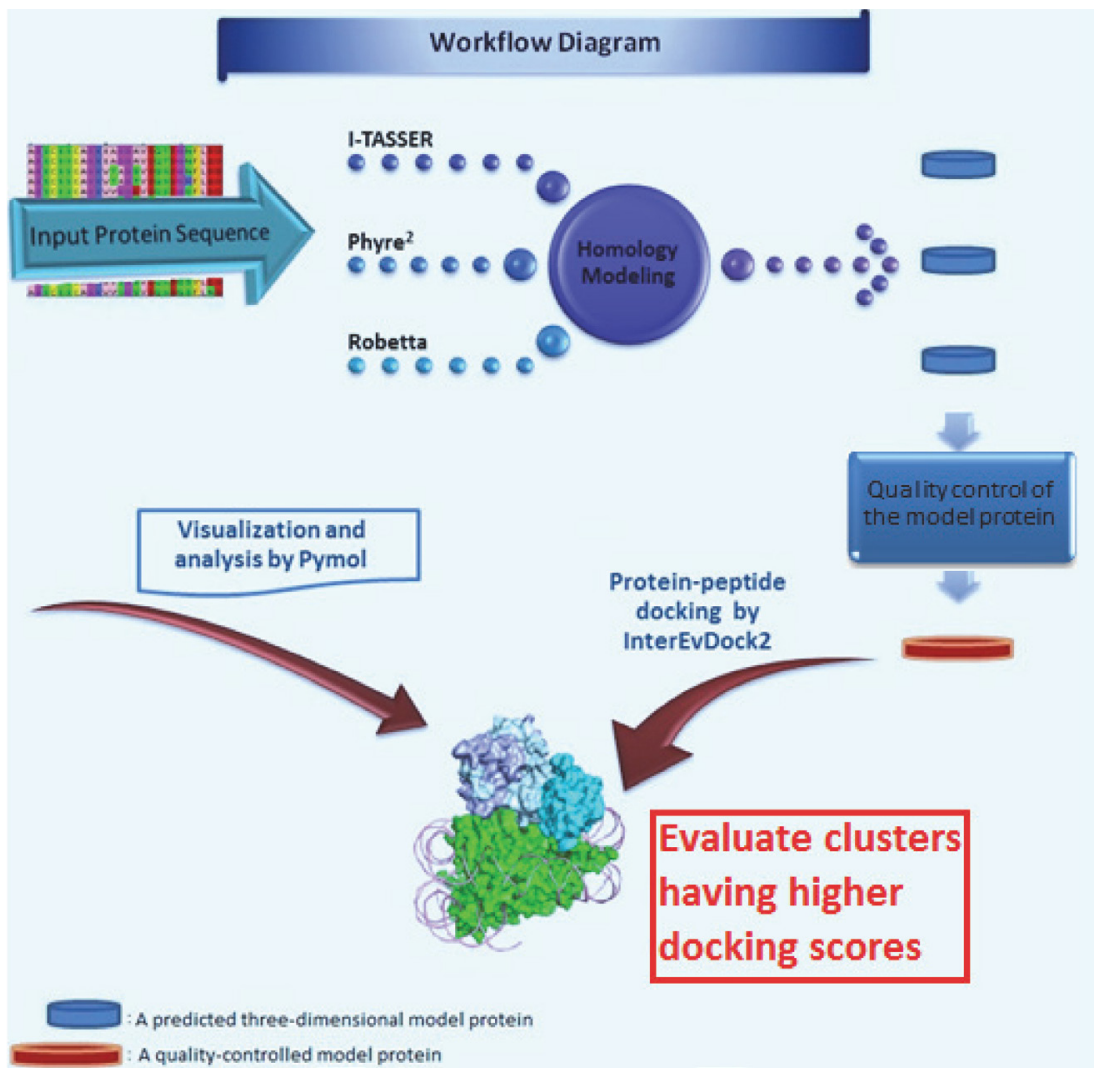

Figure 1. A pipeline of molecular docking of Aggregatin and Amyloid-beta(A $\beta)$ peptide. There are four key steps in the pipeline. First, the prediction of the 3D structure of Aggregatin. Second, the model protein structure analysis for quality. Third, protein-peptide docking by the InterEvDock2 server. Forth, the final analysis by the PyMOL software.

represent the tertiary structure proteins-peptides and analyze the docking results at the atomic structure level. The NMR monomer structures of Amyloid Beta-Peptide (1-28
$\mathrm{A} \beta)$ (PDB ID:1AMB), and (1-42 A $\beta$ ) (PDB:1IYT) from PDB (Protein Data Bank) at http://www.rcsb.org/ were retrieved for the protein-peptide interaction study. Fig.3 was

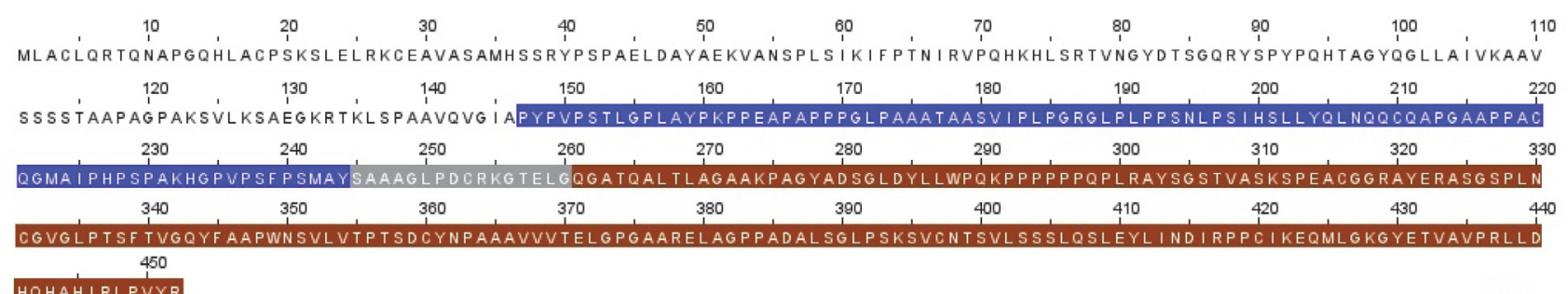

Prolin-rich domain(147-299) —:Transmembrane region (245-260) $\square$ : Extracellular region (261-452)

MEMSAT-SVM

Kyte-Doolittle

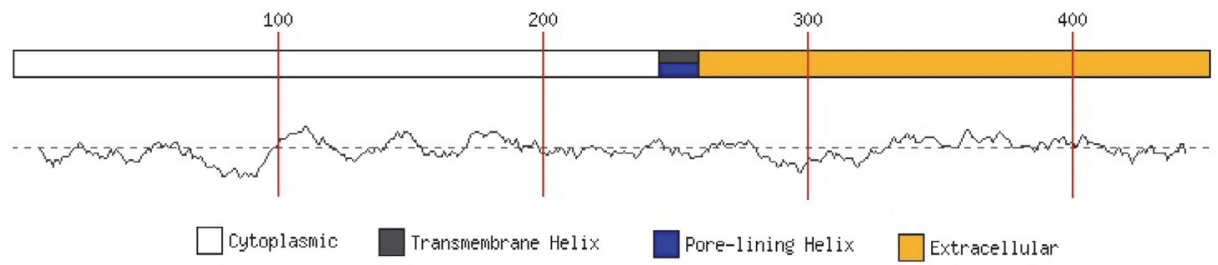

Figure 2. A.) The primary structure of FAM222A encoded Aggregatin protein. PSIPRED was used to predict the actual primary structure. The cytoplasmic part is colorless, the proline-rich region(147-299) gained from the UniProt tool is colored with navy blue. The transmembrane region (245-260 residues) is gray and the extracellular part region (261-452) is colored with brown. B.) MEMSAT-SVM shows the transmembrane helix topology and the Kyte-Doolittle scale presents the hydrophobic amino acids. 
retrieved from the Protein Data Bank in Europe (PDBe) which is available at https://www.ebi.ac.uk/pdbe/ to visualize the $\mathrm{N}$-terminal and $\mathrm{C}$ - terminal domain of Amyloid-beta peptide 42. All docking complexes were conducted by InterEvDock $2^{22-24}$ online server via using the FRODOCK ${ }^{25}$ and SOAP_PP. ${ }^{26}$

\section{Results}

\section{1. Domain Prediction Analysis}

In the domain prediction analysis with DomPred, the parts to be localized in the transmembrane region in certain series domains were predicted as hydrophobic amino acids represented by the Kyte-Doolittle scale denotes. According to the primary structure of the Aggregatin, the range 147-299 aa is a proline-rich region and bound to the membrane in a helix form, and the remained part extends as the extracellular part. Besides, its N-terminal part is in the cytoplasm, whereas the C-terminal is outside the cell and the sequence of 244-259 aa -the pore-lining part- is in the membrane (See Fig.2).

We also performed the domain prediction of the sequence of FAM222B protein. We used the GeneMANIA ${ }^{29}$ online server to search whether FAM222A is functionally related to any gene. We found that FAM222A has a shared domain with FAM222B. Thus, we also performed the domain prediction of the sequence of FAM222B protein, which -we think- would be a clue for in vitro studies (see Fig. 3). The FAM222A and FAM222B are localized in the nucleoplasm, share the same domain, and belong to the same protein family, and their alignments result per ident 49.04\% in the blastp. Although the FAM222B has been confirmed in vitro to be localized merely in the nucleoplasm, it's transmembrane and extracellular part, the glycine-rich region, and the signal peptide part domains were predicted to be in the cell membrane (not shown).

\section{2. The PDB sequence viewer of Amyloid-Beta 42}

To find out which residues is $\mathrm{N}$ - or C-terminal domain, thus the interaction between $\beta$-Amyloid ${ }_{42}$ peptide and Aggregatin at the atomic side level, we attained the $\mathrm{A} \beta_{42}$ chart retrieved from PDBe.

According to this chart, the $\mathrm{N}$-terminal domain of the $A \beta_{42}$ sequence was the first 27 residues, owing to the combination of the data from several databases such as $\mathrm{CATH}^{31}$ and SCOPE ${ }^{32}$ (See Fig.4).

\section{3. The Selection of Model Aggregatin Protein}

QMEAN tool was used to control the quality of the model protein before the docking process and determine the accuracy rate of the three bioinformatics tools selected for Aggregatin. As a result, the model protein from the Robetta was subjected to protein-peptide docking. Models retrieved from the other tools were determined to be inapplicable for the docking process.

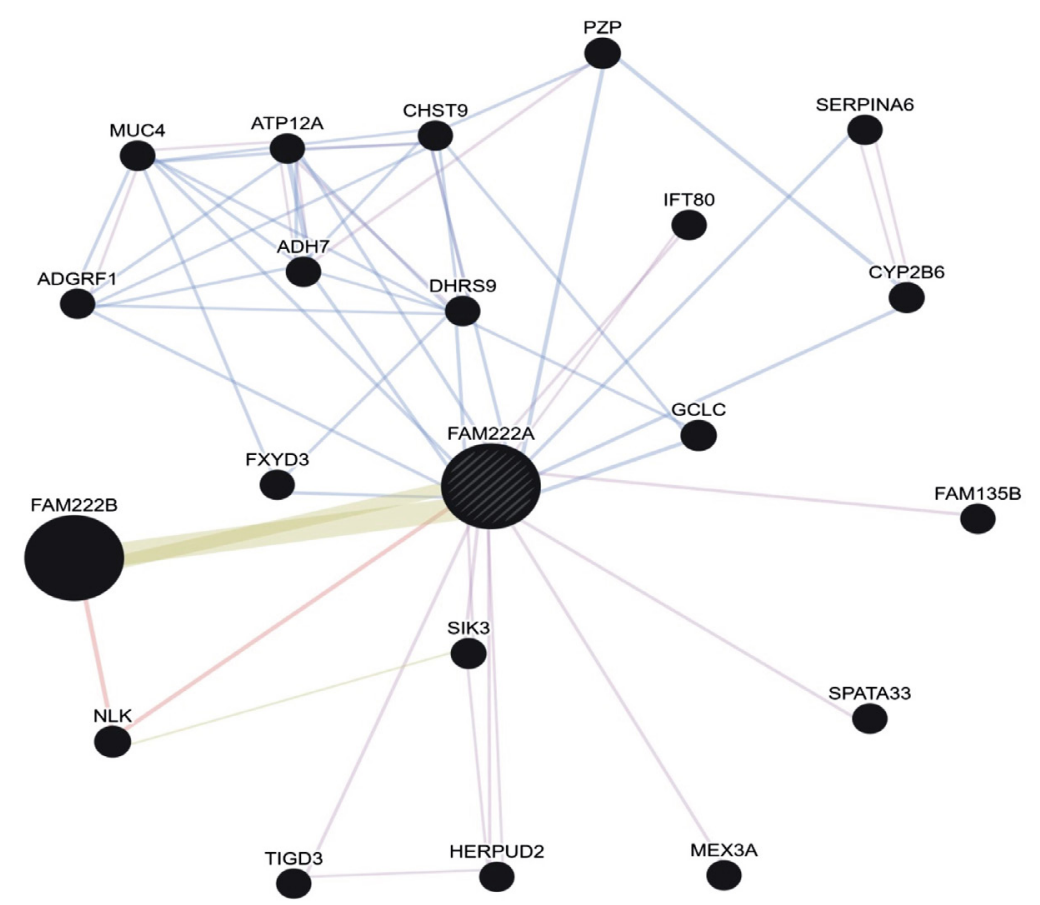

Figure 3. GeneMANIA found functionally similar genes using a wealth of genomics and proteomics data of FAM222A related genes. According to this network, between FAM222A and FAM222B have shared protein domains, and sequence similarities (0.59\%) concerning INTERPRO and PFAM. 

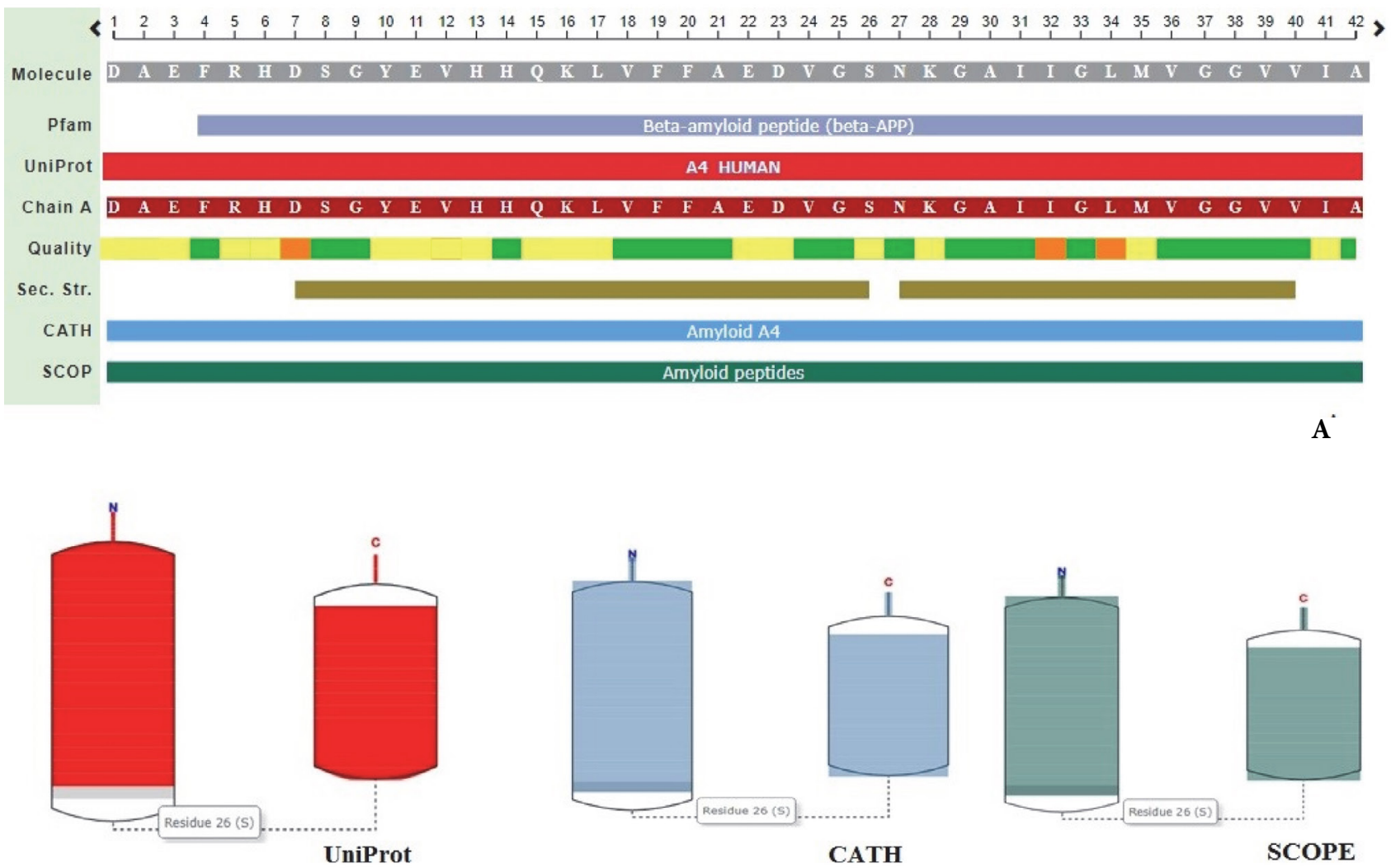

CATH

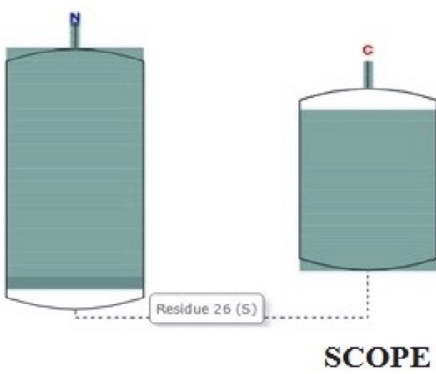

B

Figure 4. A.) The chart represents the sequence viewer of the N-terminal and C-terminal domains of 1-42 A $\beta$ peptide (PDB:1IYT). On the quality band, the residue of validation in yellow color indicates side chain or ramachandran outliers, in orange color indicates together both side chair and ramachandran outliers, and in green color represents no validation reported issue (Protein Data Bank in Europe). B.) According to some databases such as UniProt (red), CATH (blue), and SCOPE (green), 1-26 residues of A $\beta$ peptide represent the N-terminal domain, and 27-42 residues of A $\beta$ peptide represent $\mathrm{C}$ - terminal domain.

\section{4. Alignment}

Although the sequence per identity retrieved from the homology modeling by PSI-BLAST is $31-26 \%$ (see Table 1 ), there are sufficiently acceptable docking results as shown in Fig. 6-10. Besides, the sequence similarity under
$30 \%$ does not mean that the model protein retrieved from the comparative analysis will have low reliability. Some primary sequences may have been conserved, and homology modeling can predict as accurately as experimental low-resolution models. ${ }^{34}$

Table 1. The list of PSI-BLAST results of the amino acid sequence of Aggregatin. The list of homolog proteins is arranged according to their percent identities with Aggregatin. According to the outcomes, the percent identity of the proteins ranges between 31-26\%.

\begin{tabular}{|c|c|c|c|c|c|c|}
\hline $\begin{array}{l}\text { Description(Sequences with E-value WORSE } \\
\text { than the threshold) }\end{array}$ & $\begin{array}{l}\text { Max } \\
\text { Score }\end{array}$ & $\begin{array}{l}\text { Total } \\
\text { Score }\end{array}$ & $\begin{array}{l}\text { Query } \\
\text { Cover }\end{array}$ & $\begin{array}{c}\mathrm{E} \\
\text { value }\end{array}$ & $\begin{array}{l}\text { Per. } \\
\text { ident }\end{array}$ & Accession \\
\hline $\begin{array}{l}\text { Chain C, Apoptosis-stimulating of } \mathrm{p} 53 \text { protein } \\
2 \text { [Homo sapiens] }\end{array}$ & 32.3 & 32.3 & $16 \%$ & 0.95 & 26.67 & 6GHM_C \\
\hline $\begin{array}{l}\text { Chain B, APOPTOSIS STIMULATING OF P53 PROTEIN } \\
2 \text { [Homo sapiens] }\end{array}$ & 32.3 & 32.3 & $16 \%$ & 1.1 & 26.67 & 4A63_B \\
\hline Chain B, 53BP2 [Homo sapiens] & 32.3 & 32.3 & $16 \%$ & 1.1 & 26.67 & 1YCS_B \\
\hline $\begin{array}{l}\text { Chain B, Light chain (kappa) of CBTAU-24.1 } \\
\text { antibody [Homo sapiens] }\end{array}$ & 31.2 & 31.2 & $15 \%$ & 2.6 & 29.11 & 5ZIA_B \\
\hline Chain L, fAb Light chain [Mus musculus] & 30 & 30 & $14 \%$ & 5.8 & 31.34 & 5OBF_L \\
\hline Chain L, Fab Fragment, Light Chain [Mus musculus] & 29.3 & 29.3 & $17 \%$ & 9.4 & 27.72 & 1MHP_L \\
\hline Chain E, VL of Fab 11G1 [Mus musculus] & 28.5 & 28.5 & $15 \%$ & 9.4 & 29.63 & 6AJ9_E \\
\hline
\end{tabular}



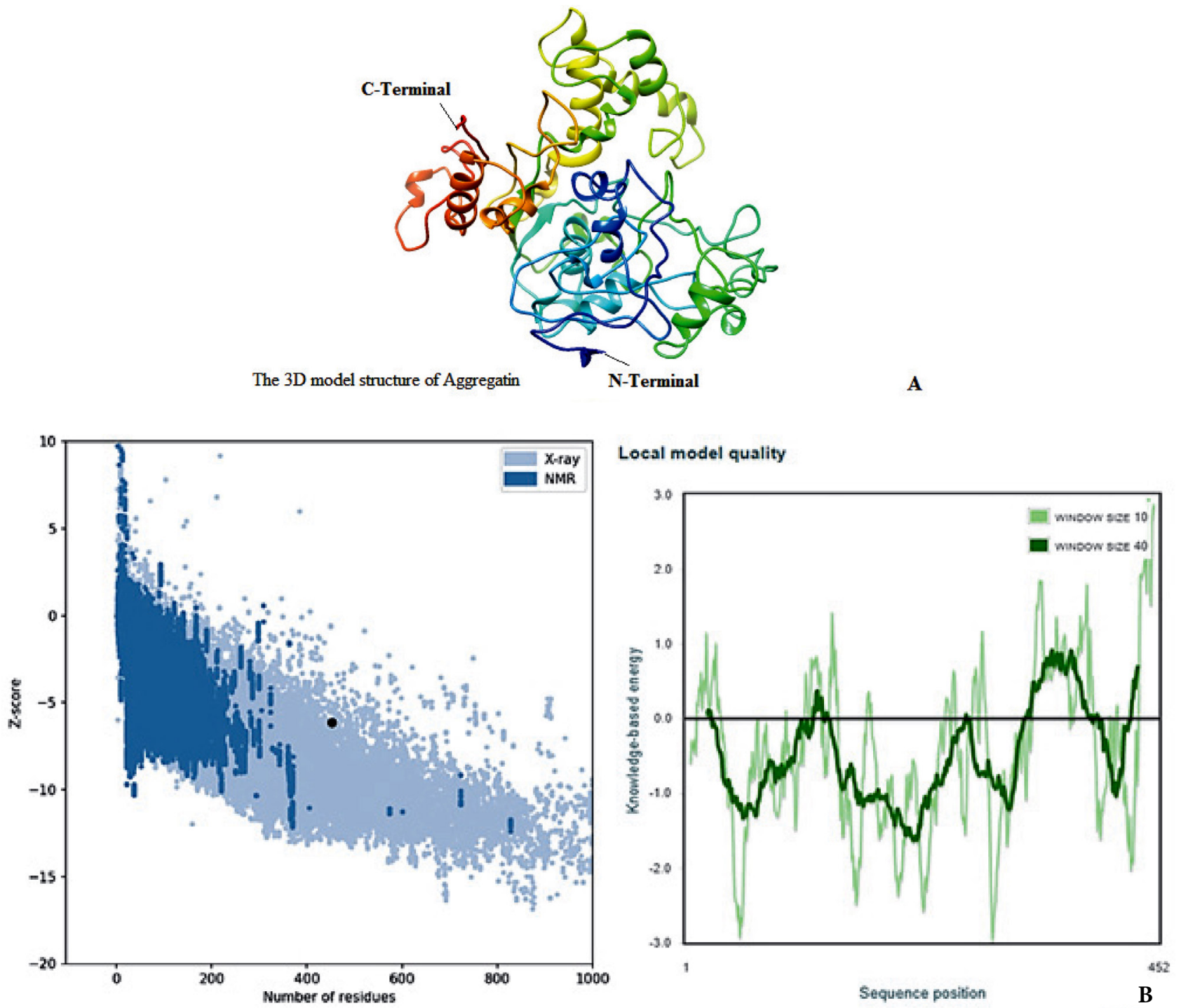

Figure 5. A.) The overall 3D structure of predicted Aggregatin. Robetta server predicted the 3D model structure of Aggregatin protein by the homology model. The model was subjected to a procedure of protein-peptide docking. The cartoon model representation and image were generated with Chimera $1.14 .^{33}$ Structures are symbolized as interactive colored ribbons to show strand and helix forms. B.) ProSA-web service analysis of Aggregatin. The black dot denotes that the input Aggregatin is between Z-score values of the experimental structures relative to the several amino acid residues and energy graph of the predicted Aggregatin. The Z-score or the overall model-quality was designated to be -6.15 in the X-ray region of the plot(Left). The other plot represents the local quality concerning the number of sequence positions (Right).

\section{5. Docking Outcomes of Aggregatin and Amyloid-Beta Peptides}

The docking score and interaction outcomes are listed in Table 2-3. As shown in the representative models from 8 best clusters in Table 2, IES1_A and FRODOCK1_C by higher scores and SOAP_A by lower energy score are top consensus complexes. According to the docking online server, in IES6_ B docking complex, the residues of GLN442, HIS443 (Aggregatin chain) and HIS13, PHE20 (A $\beta$ peptide) between the top 5 residues (on each chain) predicted to be involved in contacts based on the consensus of top 10 models from each method (see Figure 6.A, B, C). As an overall result of docking,
Aggregatin protein contacted the residues in the C-terminal region from the $\mathrm{N}$-terminal region of the amyloid-beta 42 .

Representative models from 7 best clusters were shown in Table 3, FRODOCK2_A and IES2_B 1 docking complexes, and SOAP_A $\mathrm{A}_{2}$ are the top consensus complexes. According to the docking online server, IES6_ B docking complex interacts the residue ARG447, GLY429 (Aggregatin chain in C-terminal region) and HIS13, LYS16 (A $\beta$ peptide in $\mathrm{N}$-terminal region) between the top 5 residues (on each chain) predicted to be involved in contacts based on the consensus of top 10 models from each method (see Fig. 9B and Fig. 10 B2). 
Table 2. Probable interface residues on each protein between the model of Aggregatin and $A \beta_{42}$ peptides. IES and FRODOCK2 score (higher is better), SOAP_PP score (lower is better).

\begin{tabular}{llll}
\hline Docking complexes & Residue number $\left(\mathbf{A} \boldsymbol{\beta}_{\mathbf{4}}\right)$ & Aggregatin & Docking score \\
\hline IES1_A & HIS6 & TYR303 & 423.1 \\
IES6_B & HIS13, LEU17, PHE20 & ASP359, HIS443 GLN442 & 372.17 \\
IES9_C & TYR10, HIS13 & ALA365, VAL333 & 360.15 \\
SOAP_B & TYR10, VAL18 & ARG447, HIS443 & -16473.52 \\
SOAP_A & HIS6, GLY9, GLY37 & ARG447, HIS445,LEU353 & -16148.85 \\
FRODOCK2_A & GLY29, ILE32 & GLN442 & 2267.23 \\
FRODOCK4_B & ARG5, HIS13 & PRO147, TYR321 & 2062.62 \\
FRODOCK1_C & GLU11, LYS16, GLU22 ILE31, LEU34 & TYR148, ARG319, SER312, SER241 & 2290.05 \\
\hline
\end{tabular}

Table 3. The interface residues on each protein between the model of Aggregatin and A $\beta_{28}$ peptides. IES and FRODOCK2 score (higher is better), SOAP_PP score (lower is better).

\begin{tabular}{llll}
\hline Docking complexes & Residue number $\left(\mathbf{A} \boldsymbol{\beta}_{\mathbf{2 8}}\right)$ & Aggregatin & Docking score \\
FRODOCK2_A & ARG5, TYR10 & LYS135, GLY155 & 1727.14 \\
FRODOCK4_B & HIS13, LYS16 & ARG447, GLY429 & 1699.13 \\
FRODOCK8_C & TYR10 & HIS445 & 1646.18 \\
SOAP_A & LYS16 & ASP284,TYR285,CYS360 & -15623.78 \\
SOAP_A & GLN15 & ASN195 & -15795.12 \\
IES2_B & TYR10, HIS6 & LYS135, ARG133 & 236.81 \\
IES3_B & HIS13, LYS16 & ARG447, GLY429 & 226.48 \\
\hline
\end{tabular}

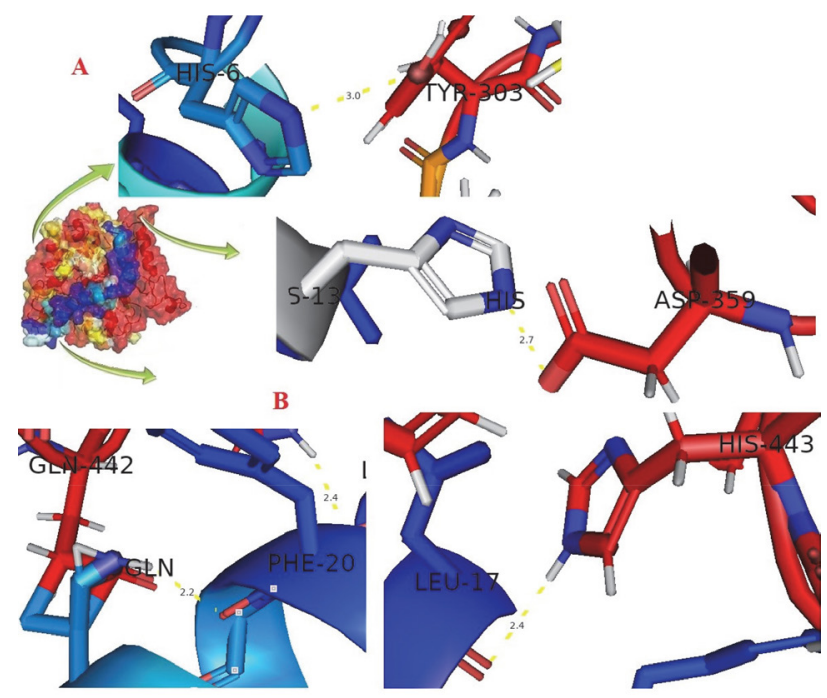

The results of both $A \beta 42$ and $A \beta 28$ docking with $\mathrm{Ag}$ gregatin protein are ARG5 HIS6, HIS13, and TYR10 residues that commonly interact. Binding modes of Aggregatin with $A \beta_{42}$ and $A \beta_{28}$ by molecular docking simulation

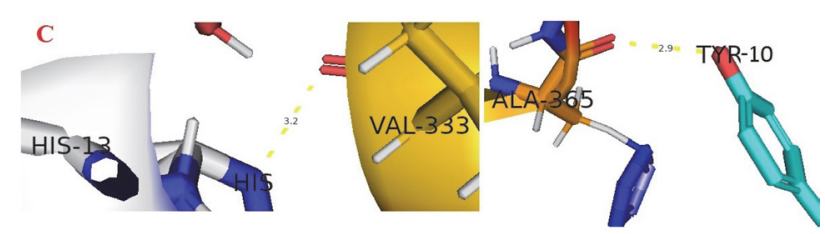

Figure 6. The InterEvDock 2 model results of Aggregatin and A $\beta 42$ peptides. The docking complex is represented in a surface representation, colored by (A $\beta 42$ in blue color and Aggregatin in red) A.) Aggregatin(TYR303) interacts with the residue HIS6 of A 342 having the highest energy score. B.) Aggregatin(ASP359) interacts with HIS13, GLN442 with PHE20, and HIS443 with LEU17. C.) Aggregatin(VAL333) interacts with HIS13, and ALA365 with TYR10 in the N-terminal domain of A $\beta 1-42$ peptide. The highest score belongs to the model in section A (see Table 2).

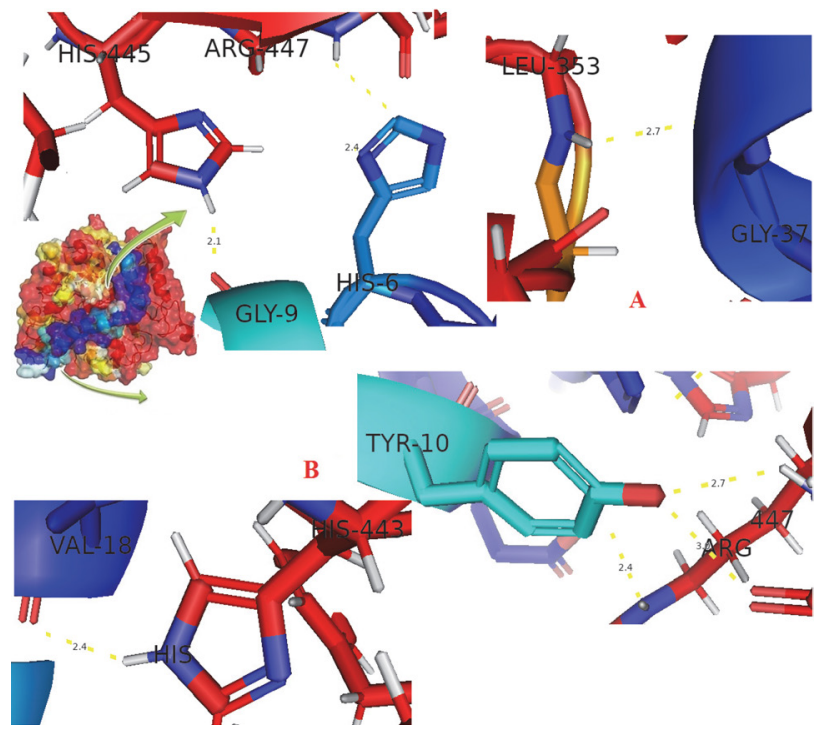

Figure 7. The SOAP_PP model results of Aggregatin and A $\beta 42$ peptides. Binding modes of Aggregatin and $\mathrm{A} \beta_{42}$ in surface representations are shown. A.) Aggregatin(HIS445) interacts with GLY9, ARG447 with HIS6, LEU353 with GLY37 of A 422 with a lower energy score. B.) Aggregatin(ARG447) interacts with TYR10 and HIS443 with VAL18 of A $\beta_{42}$. HIS6, GLY9 (of section A), and TYR10, and VAL18 (of section B) are in the N-terminal domain of the $A \beta_{1-42}$ peptide whereas GLY37 in section $A$ is in the C-terminal domain of the $A \beta_{42}$. 


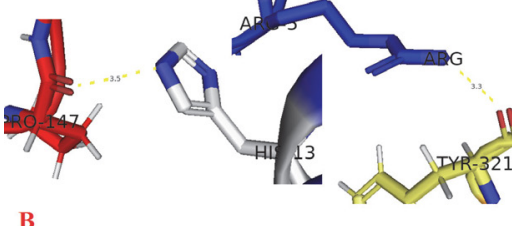

B

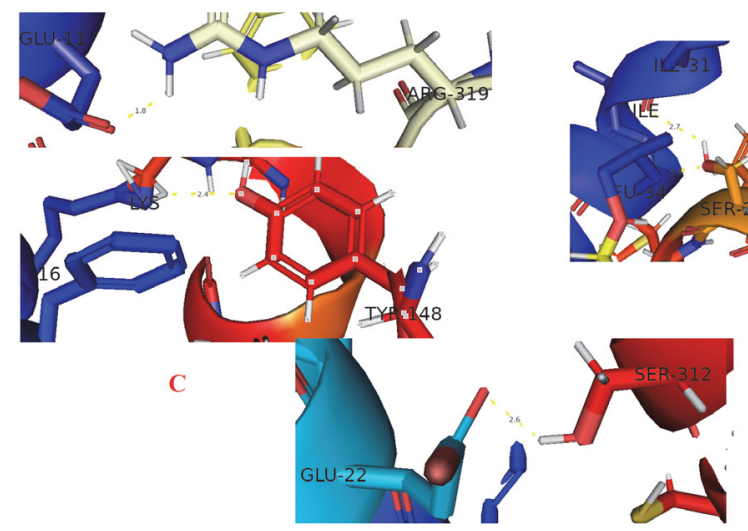

Figure 8. The FRODOCK 2 model result of Aggregatin and $A \beta 42$ peptides. Binding modes of Aggregatin and $A \beta 42$ in surface representations are shown. A.) Aggregatin(GLN442) interacts with the residue GLN29 and ILE32 of A $\beta$. B.) Aggregatin(TRY321) interacts with ARG5, PRO147 with HIS13. C.) Aggregatin(TYR148) interacts with LYS16, ARG319 with GLU11, and SER312 with GLU22, and SER241 with ILE31/LEU34. In this binding mode of the simulation, GLU11, LYS16, and GLU22(of section A) and ARG5, and HIS13 (of section $B$ ) are in the N-terminal domain of $A \beta 1-42$ peptide whereas GLY29, ILE32, and ILE31, and LEU34 (of section C) are in the C-terminal domain of $\mathrm{A} \beta_{42}$.

are shown in Figure 6-10. Binding mode is colored by red (Aggregatin) and blue (amyloid-beta). Figures are generated by PyMOL.

\section{Discussion}

This research seeks to address the association of Aggregatin protein, whose function and three-dimensional structure is not characterized yet, with Alzheimer's pathology using in silico analysis. The interaction of Aggregatin with Amyloid-beta and lesion-forming complex of both was elucidated since an extracellular aggregate formation observed in Alzheimer's pathology. ${ }^{5}$ Even though Aggregatin is expressed in the nerve cells, it remains uncertain from which part of the cell and compartment it is released and how it forms a core with the extracellular amyloid-beta plaques. Yet, the in vitro studies carried out so far showed that Aggregatin is located in the nucleoplasm and plasma membrane of the cell parts as well as in the mitochondria and focal adhesion. ${ }^{27}$

Protein structures may comprise of multiple intense foldable parts named domains. These domains contain typical hydrophobic cores, can be folded free of each other, and frequently connected to establish distinct functions. ${ }^{28}$

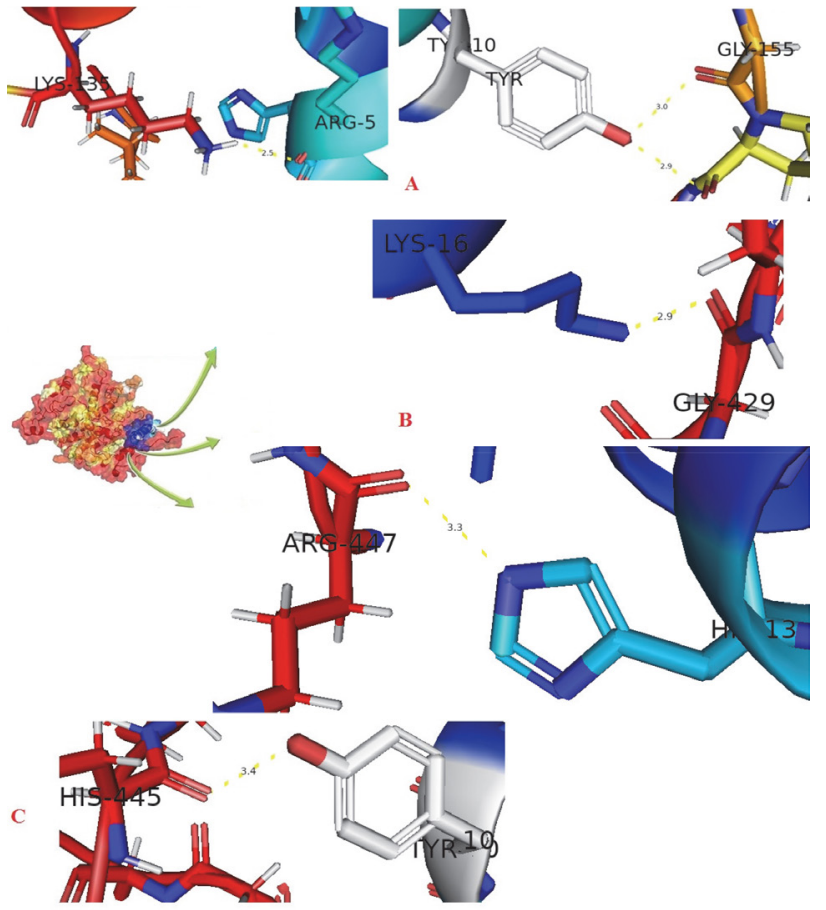

Figure 9. The FRODOCK2 model results of Aggregatin and $A \beta_{28}$ peptides. Binding modes of Aggregatin and $A \beta 42$ in surface representations are shown. A.) Aggregatin(LYS135) interacts with the residue of ARG5, GLY155 with TYR10 of the $A \beta_{28}$. Aggregatin(LYS429) interacts with LYS16, ARG447 with HIS13 of the A $\beta_{28}$. C.) Aggregatin(HIS445) interacts with TYR10 of the $A \beta_{28}$. In this binding mode, TYR10, HIS13, and ARG5 residues are common to both $\mathrm{A} \beta_{28}$ and $\mathrm{A} \beta_{42}$ in docking results.

For this purpose, our first approach in this study was to predict the domain of the Aggregatin's aa sequence and find out if there is a potential significant aa sequence such as a signal peptide being used as the protein binding interfaces.

Domain prediction using the actual sequence may lead to crucial consequences linking theoretical knowledge to the experimental studies. During the structural research of the proteins by experimental studies such as NMR or X-ray crystallography, the achievement is limited to single-domain proteins rather than full multi-domain proteins. ${ }^{30}$ Thus, for structural biologists, it would be meaningful to analyze the primary structure of proteins as it would be more logical to classify single-domain proteins in a distinct category than the multi-domain ones. In our results, Computational analysis of the membrane localization of Aggregatin protein validates in vitro studies (see Fig. 2).

Robetta is a protein structure prediction service continuously evaluated with CAMEO (Continuous Automated Model EvaluatiOn), which constantly assesses the accuracy and reliability of the prediction. Among other prediction tools of CAMEO, Robetta and QMEAN are the first-line by time-based statistical confidence and reliable performances. In addition to these tools, the ProSA-web 


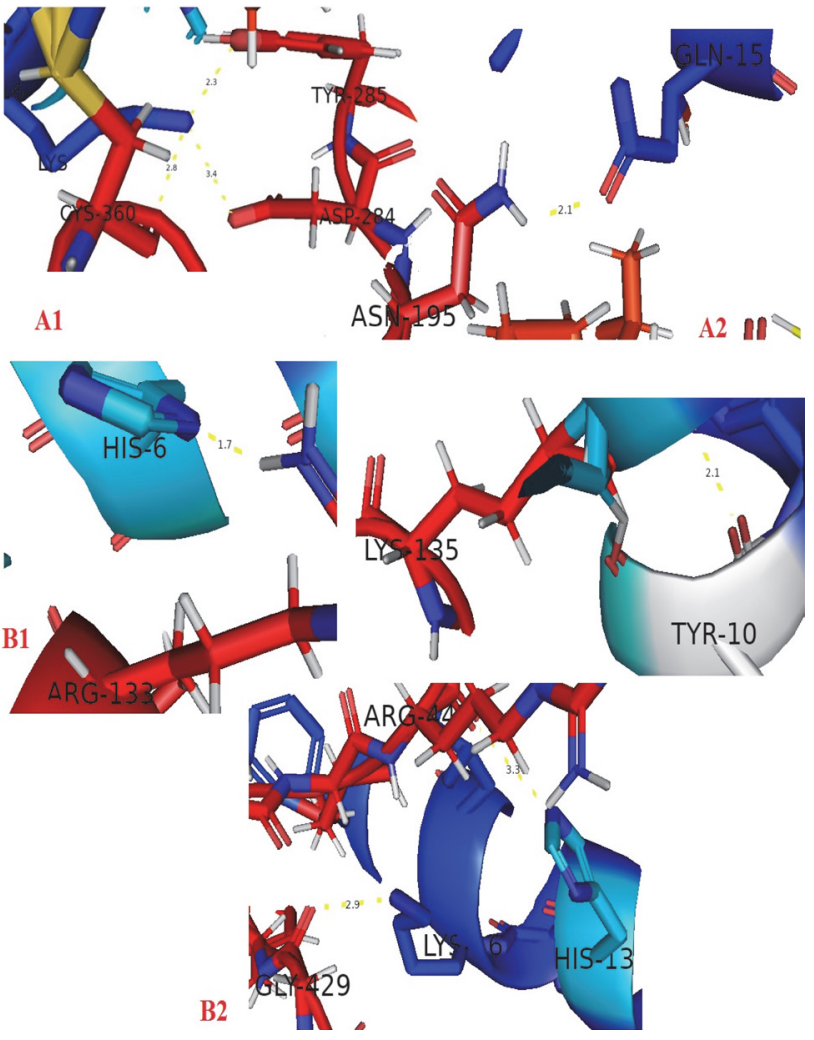

Figure 10. The SOAP and IES model results of Aggregatin and $A \beta_{28}$ peptides. A1.) Aggregatin (ASP284, TYR285, CYS360) interacts with the residue of LYS16 of $A \beta_{28}$. A2.) The interaction is between Aggregatin(ASN195) and GLN15 of $A \beta_{28}$ B1.) The docking is between the residue of Aggregatin(ARG133)-HIS6 $\left(\mathrm{A} \beta_{28}\right)$ and LYS135-TYR10. B2.) In the binding mode, Aggregatin(GLY447) interacts with the residue of HIS13 and GLY429 with LYS16 of A $\beta_{28}$. In this simulation, TYR10, HIS13, and LYS16, and HIS6 residues are common to both $\mathrm{A} \beta_{28}$ and $\mathrm{A} \beta_{42}$ in docking results.

was used to verify the quality of the model protein. The overall model quality or the Z-score was designated to be -6.15 as shown in Figure 5. The Z-score indicates total model quality and calculates the deviation of the total energy of the structure regarding the energy distribution that comes from random conformations (see Figure 5A, B). Consequently, the model Aggregatin is reliable to subject to molecular docking procedure.

The structural simulations of the protein-protein interactions are fundamental to explain how each cell machinery assembles at the molecular level. These simulations may be helpful to assess multiple sequence alignments and their structures, thus unmask the binding interfaces when neighboring proteins have possible homologous sequences. In the docking procedure of the current study, a free online tool, InterEvDock 2 was used for protein-protein docking operation and a potential InterEvScore was produced to combine evolutionary information. The InterEvScore has determined the heteromeric protein interfaces and the integration of the evolutionary information retrieved from the multiple sequence alignments of each protein in the clusters with a residual-based multi-body statistical potential.

In this online server, docking searching is systematically applied using the FRODOCK 2 and the results are re-calculated by InterEvScore ${ }^{24}$ and SOAP_PP atom-based statistical potential to boost the confidence of the predictions.

As mentioned before, we predicted acceptable clusters using the InterEvDock 2 server. This server predicts the top 10 consensus complexes for 239 out of 812 tested cases. The selected clusters for each of Aggregatin-A $\beta_{42}$ peptide and $A \beta_{28}$ peptide are represented in Tables 2 and 3 . Besides, the InterEvDock 2 server predicts the top 5 of residues interacting at the interface of a complex by a scoring system for the top 10 clusters of 30 models retrieved from InterEvDock2, FRODOCK2, and SOAP_PP.

In our study, we aimed to address the docking of $\mathrm{Ag}$ gregatin with both $A \beta_{42}$ and $A \beta_{28}$ peptides since both peptides are involved in the amyloidosis process. $A \beta_{28}$ peptide is the major part of the amyloidosis process as it is deposited in $\mathrm{AD}$ in the early phase of amyloidosis. Here, we revealed that the side chains of HIS13 and LYS16 in the $\mathrm{A} \beta_{28}$ are localized on the same face of the helix. Interestingly enough, the docking process with HIS13 and LYS16 residues of the $\mathrm{A} \beta_{28}$ peptide is among the highest binding energy results as shown in Table 3. The interaction of $A \beta_{42}$ peptide with $\mathrm{Ag}$ gregatin through LYS16 HIS13 residues retrieved from FRODOCK2 outcomes also possesses higher binding energy (See Table 2). Our expectation in the study was to find out whether our docking results were compatible with the in vitro analysis performed by Yan et al..$^{5}$ and if Aggregatin binds to amyloid-beta from the $\mathrm{N}$-terminal region.

Taken together, we reached the adequately satisfactory docking results as represented in Figures 6-10. As shown in Figure 4 , the $\mathrm{N}$-terminal domain of $\mathrm{A} \beta_{42}$ peptide is composed of the first 1-26 amino acids as we have demonstrated the 3D model structure of Aggregatin and its both $\mathrm{N}$ - and C-terminal ends. When comparing docking results with amyloid beta- 42 and -28 , the common residues that Aggregatin and amyloid peptides interact are ARG5, HIS6, and HIS13, and TYR10. These residues are in the $\mathrm{N}$ - terminal domain of $A \beta 42$. The interaction of ARG5 and TYR10 in A $\beta 28$ by Aggregatin and HIS6 and TYR10 in A $\beta 28$ by Agregatin has higher binding energy score the other one (see Table 3 ). The binding mode of TYR303 in Aggregatin has the highest energy score with the residue HIS6 of A $\beta 42$ (See Fig. 6A). Besides, the molecular simulation of Aggregatin(ARG447) with TYR10 and HIS443 with VAL18 of A $\beta 42$ have better energy docking scores (See Fig. 7B). The critical point is which residue in the $\mathrm{N}$-terminal domain of $\mathrm{A} \beta 42$ interacts with a higher binding energy in the calculation. Our calculation results show that the Amyloid Beta- 42 generally interacts with its residues in the C-terminal region of Aggregation. As three scoring programs in the docking process have confirmed each other, we concluded that the models with the highest 
binding energy are the complexes that interact with residues (1-26) in the N-terminal region of the Amyloid beta.

\section{Conclusion}

Alzheimer's disease has no known specific remedy yet, and the treatment is limited to slowing the progression of the disease while increasing the quality of life. Unfortunately, there is no predictable result for Alzheimer's patients since some experience cognitive problems slightly whereas the others may undergo a quicker onset of symptoms with faster disease progression. Here, the strategies on how to implement the therapies have gained importance with molecular and cellular approaches. We claim that two different lengths of the amyloid-beta peptide with known NMR structures are docked to the model Aggregatin, and have critical interactions between residues measured by the computational calculation but the fact that the two proteins interact, is not enough to link this process to the amyloid plaque formation. This interaction might only suggest a role of Aggregatin in the amyloid-beta pathway, but in vivo and in vitro experiments should be performed to explain its actual role in plaque formation in Alzheimer's pathology, if any. The domain analysis of Aggregatin supports its localization within the cell as confirmed in vitro. This study will help us to understand the possible conformational changes in the three-dimensional structure of Aggregatin, which might be screened by the experimental methods as mutations such as deletions and single nucleotide polymorphisms.

\section{Declarations}

Funding: Not Applicable

Conflict Of Interest: We have no conflict of interest to declare.

Available of Data: Analysis data is ready to be shared upon request

Code Availability: Not Applicable

Authors Contributions: Both authors hypothesized the subject. Besli performed the analysis. Both authors evaluated the results and wrote the manuscript.

\section{Reference}

1. K. Dassel, J. Butler, J. Telonidis, L. Edelman, Educ. Gerontol. 2020, 46, 150-157. DOI:10.1080/03601277.2020.1717079

2. R. E. Tanzi, Cold Spring Harb. Perspect. Med. 2012, 2, a006296. DOI:10.1101/cshperspect.a006296

3. E. Nichols, C. E. I. Szoeke, S. E. Vollset, N. Abbasi, F. Abd-Allah, J. Abdela, M. T. E. Aichour, R. O. Akinyemi, F. Alahdab, S. W. Asgedom, et al., Lancet Neurol. 2019, 18, 88-106.

4. A. Association, Alzheimer's Dement. 2019, 15, 321-387. DOI:10.1016/j.jalz.2019.01.010
5. T. Yan, J. Liang, J. Gao, L. Wang, H. Fujioka, X. Zhu, X. Wang, Nat. Commun. 2020, 11, 1-16.

DOI:10.1038/s41467-019-13962-0

6. D. J. Selkoe, Annu. Rev. Neurosci. 1994, 17, 489-517. DOI:10.1146/annurev.ne.17.030194.002421

7. R. J. O’Brien, P. C. Wong, Annu. Rev. Neurosci. 2011, 34, $185-$ 204. DOI:10.1146/annurev-neuro-061010-113613

8. A. Viswanathan, S. M. Greenberg, Ann. Neurol. 2011, 70, 871-880. DOI:10.1002/ana.22516

9. G. Chen, T. Xu, Y. Yan, Y. Zhou, Y. Jiang, K. Melcher, H. E. Xu, Acta Pharmacol. Sin. 2017, 38, 1205-1235.

DOI:10.1038/aps.2017.28

10. G. G. Glenner, C. W. Wong, Biochem. Biophys. Res. Commun. 1984, 120, 885-890. DOI:10.1016/S0006-291X(84)80190-4

11. D. T. Jones, J. Mol. Biol. 1999, 292, 195-202. DOI:10.1006/jmbi.1999.3091

12. A. Roy, A. Kucukural, Y. Zhang, Nat. Protoc. 2010, 5, 725. DOI:10.1038/nprot.2010.5

13. L. A. Kelley, S. Mezulis, C. M. Yates, M. N. Wass, M. J. E. Sternberg, Nat. Protoc. 2015, 10, 845.

DOI:10.1038/nprot.2010.5

14. Y. Song, F. DiMaio, R. Y.-R. Wang, D. Kim, C. Miles, T. J. Brunette, J. Thompson, D. Baker, Structure 2013, 21, 1735-1742. DOI:10.1016/j.str.2013.08.005

15. S. Raman, R. Vernon, J. Thompson, M. Tyka, R. Sadreyev, J. Pei, D. Kim, E. Kellogg, F. DiMaio, O. Lange, et al., Proteins Struct. Funct. Bioinforma. 2009, 77, 89-99.

DOI: $10.1002 /$ prot. 22540

16. A. Waterhouse, M. Bertoni, S. Bienert, G. Studer, G. Tauriello, R. Gumienny, F. T. Heer, T. A. P. de Beer, C. Rempfer, L. Bordoli, et al., Nucleic Acids Res. 2018, 46, W296-W303. DOI:10.1093/nar/gky427

17. M. Wiederstein, M. J. Sippl, Nucleic Acids Res. 2007, 35, W407-W410. DOI:10.1093/nar/gkm290

18. S. F. Altschul, T. L. Madden, A. A. Schäffer, J. Zhang, Z. Zhang, W. Miller, D. J. Lipman, Nucleic Acids Res. 1997, 25, 3389-3402. DOI:10.1093/nar/25.17.3389

19. D. T. Jones, D. Cozzetto, Bioinformatics 2015, 31, 857-863. DOI:10.1093/bioinformatics/btu744

20. A. M. Waterhouse, J. B. Procter, D. M. A. Martin, M. Clamp, G. J. Barton, Bioinformatics 2009, 25, 1189-1191.

DOI:10.1093/bioinformatics/btp033

21. Schrödinger, LLC, The $\{P y M O L\}$ Molecular Graphics System, Version 1.8, 2015.

22. C. Quignot, J. Rey, J. Yu, P. Tufféry, R. Guerois, J. Andreani, Nucleic Acids Res. 2018, 46, W408-W416. DOI:10.1093/nar/gky377

23. J. Yu, M. Vavrusa, J. Andreani, J. Rey, P. Tufféry, R. Guerois, Nucleic Acids Res. 2016, 44, W542-W549. DOI:10.1093/nar/gkw340

24. J. Andreani, G. Faure, R. Guerois, Bioinformatics 2013, 29, 1742-1749. DOI:10.1093/bioinformatics/btt260

25. E. Ram \’irez-Aportela, J. R. López-Blanco, P. Chacón, Bioinformatics 2016, 32, 2386-2388.

DOI:10.1093/bioinformatics/btw141 
26. G. Q. Dong, H. Fan, D. Schneidman-Duhovny, B. Webb, A. Sali, Bioinformatics 2013, 29, 3158-3166.

DOI:10.1093/bioinformatics/btt560

27. M. Uhlén, L. Fagerberg, B. M. Hallström, C. Lindskog, P. Oksvold, A. Mardinoglu, Å. Sivertsson, C. Kampf, E. Sjöstedt, A. Asplund, et al., Science (80-. ). 2015, 347, 1260419.

DOI:10.1126/science.1260419

28. J. S. Richardson, in Adv. Protein Chem., Elsevier, 1981, pp. 167-339. DOI:10.1016/S0065-3233(08)60520-3

29. D. Warde-Farley, S. L. Donaldson, O. Comes, K. Zuberi, R. Badrawi, P. Chao, M. Franz, C. Grouios, F. Kazi, C. T. Lopes, et al., Nucleic Acids Res. 2010, 38, W214-W220.

DOI:10.1093/nar/gkq537
30. K. Bryson, D. Cozzetto, D. T. Jones, Curr. Protein Pept. Sci. 2007, 8, 181-188. DOI:10.2174/138920307780363415

31. T. E. Lewis, I. Sillitoe, N. Dawson, S. D. Lam, T. Clarke, D. Lee, C. Orengo, J. Lees, Nucleic Acids Res. 2017, 46, D435-D439. DOI:10.1093/nar/gkx1069

32. N. K. Fox, S. E. Brenner, J.-M. Chandonia, Nucleic Acids Res. 2013, 42, D304-D309. DOI:10.1093/nar/gkt1240

33. E. F. Pettersen, T. D. Goddard, C. C. Huang, G. S. Couch, D. M. Greenblatt, E. C. Meng, T. E. Ferrin, J. Comput. Chem. 2004, 25, 1605-1612. DOI:10.1002/jcc.20084

34. D. Petrey, Z. Xiang, C. L. Tang, L. Xie, M. Gimpelev, T. Mitros, C. S. Soto, S. Goldsmith-Fischman, A. Kernytsky, A. Schlessinger, et al., Proteins Struct. Funct. Bioinforma. 2003, 53, 430-435. DOI:10.1002/prot.10550

\section{Povzetek}

Alzheimerjeva bolezen je glavna nevrodegenerativna bolezen, katere razširjenost se po vsem svetu povečuje, vendar njen molekularni mehanizem ostaja nejasen. Obstaja nekaj znanstvenih dokazov, da je molekularna kompleksnost patofiziologije Alzheimerjeve bolezni povezana s tvorbo zunajceličnih plakov amiloida-beta v možganih. Nova navzkrižna fenotipska asociacijska analiza s slikovno genetiko je opisala gen za dovzetnost za možgansko atrofijo FAM222A, in protein Aggregatin, ki ga kodira FAM222A, v interakciji s peptidom amiloid-beta $(A \beta)(1-42)$ prek njegove N-končne $\mathrm{A} \beta$-vezavne domene, kar olajša agregacijo $\mathrm{A} \beta$. Funkcija proteina Aggregatina ni znana, njegova tridimenzionalna struktura pa še ni bila eksperimentalno določena. Naš cilj je bil podrobno proučiti medsebojno interakcijo Aggregatina in A $\beta$ $\mathrm{z}$ in silico analizo, vključno s 3D-analizo napovedovanja strukture proteina Aggregatina s homolognim modeliranjem. Naša analiza je potrdila interakcijo C-terminalne domene modelnega proteina $\mathrm{z}$ N-terminalno domeno $\mathrm{A} \beta$. To je prvi poskus dokazovanja interakcije Aggregatina z A $\beta$. Pridobljeni rezultati so potrdili in vitro in in vivo poročila raziskav, ki trdijo, da FAM222A pomaga olajšati agregacijo peptida $A \beta$.

Except when otherwise noted, articles in this journal are published under the terms and conditions of the Creative Commons Attribution 4.0 International License 